\title{
Commentary on Harrison: "Social Mechanisms of Stylistic Change"
}

\author{
SAMANTHA BURGESS[1] \\ Ohio State University
}

\begin{abstract}
This is a review of Harrison's (2021) paper "Social Mechanisms of Stylistic Change: A Case Study from Early 20th-Century France." In this study, Harrison found that the Apaches, a group of composers known for pushing stylistic boundaries in 20th-century France, employed slightly more instances of notated meter change in their music than a control group of their peers, but that the use of notated meter change also depended on other factors such as composers' generational membership. This commentary primarily explores Harrison's methodologies: while the stringent definitions Harrison defines for each variable in her studies allow for specificity in the statistical analyses, they leave out a large portion of perceptually relevant data that would lend greater musicological generalizability to the results presented.
\end{abstract}

Submitted 2021 February 16; accepted 2021 February 17.

Published 2021 June 28; https://doi.org/10.18061/emr.v15i3-4.8134

KEYWORDS: meter, style change, corpus analysis, social network analysis, Apaches

IN recent years, theorists and musicologists have turned to empirical methods of studying musical style change. In addition to Harrison (2021), notable examples of this include Jacoby \& McDermott (2017), Janssen (2018), and Shanahan \& Albrecht (2019). Harrison (2021) situates musical characteristics within interdisciplinary models of social change and uses empirical tests to analyze sources and patterns of style change. Specifically, Harrison (2021) uses notated meter change as a quantifiable feature of stylistic change amongst a group of French composers known as the Apaches. She adapts David Huron's (2001) definition of a stylistic feature, further contextualizing this with Leonard Meyer's (1989) work discussing musical constraints and strategies. Social change in music is theorized using Labov's (1972) ideas - adapted in this case, to music - that changes in language are driven by social factors.

Harrison (2021, p. 163) defines a stylistic feature as a "replication of patterning that is described and delimited according to statistical regularity" and which is perceptually salient. In the music of $20^{\text {th }}$ century France, metrical complexity was a non-normative stylistic feature. Therefore, Harrison (2021) hypothesizes that the Apaches, who-influenced by Debussy and the emerging post-impressionist avantgarde - were known as musical progressives and would likely employ metrical changes more frequently than a control group of their peers. Metrical complexity was quantified as notated meter change. In the present study, notated meter change was measured by "meter change rate," or the number of meter changes divided by the total number of measures in each piece. Overall, Harrison (2021) found slight differences in the meter change rate between the Apaches and a control outgroup, however, this effect size is small, and the Apaches do not significantly differ from their generational peers. These results were then recontextualized with musicological evidence and suggest that the Apaches were early proponents of a broader stylistic trend.

\section{METHODOLOGICAL CONSIDERATIONS}

One of this study's greatest strengths is that it is rooted in a historical, musicological observation, which allows for generalization and recontextualization of the results. The well-documented social and aesthetic coherence of the Apaches creates a compelling musicological question for an empirical study of stylistic change. However, a common difficulty with such studies is maintaining musicological relevance while also employing rigorous statistical analyses, and Harrison aims to strike a balance between the two by giving highly specific parameters for her methodology. The question itself is succinct, focusing only on composers from France and using a precisely quantifiable stylistic feature. The corpus is also well-defined, using only 
piano music, randomly sampling the control group, controlling for the impact of multimovement works on the results. Additionally, the study employs a metric for meter change that gives equal weight to pieces of differing lengths.

In empirical studies of musical style or performance, it is beneficial to start with a narrow scope, as Harrison has done, and then slowly expand the points of inquiry to get a broader view of the musicological or social issue at hand. Harrison carefully limits the methodology so that the initial inquiry does not become unmanageably large. On the other hand, I would argue that the study could also have engaged more deeply with the limitations inherent in the empirical study of musicological topics. Somewhat paradoxically for studies of this nature, engaging with the limitations of one's methodology offers a richer musicological perspective because it requires the researcher to consider alternative quantifiable elements of the score that also address the question at hand. Ultimately, these considerations provide further lines of inquiry and help develop a more detailed musicological picture. This is an important step to take given the difficulties faced in applying objective statistical measures to subjective artistic ideas.

An example of one such limitation in the present study is the idea of perceptual saliency. In her definition of stylistic features, Harrison states that "statistical significance of a feature is only meaningful if it ties to other significances, such as perceptual saliency, potential to be generalized and realized in many different concrete strategies, and usefulness for reaching specific aesthetic goals or fulfilling specific functions" (p. 163). Her main argument for the use of notated meter change is that it is a perceptually salient event; however, the nature of "perceptual salience" in this case is poorly defined. It is unclear whether the "salience" of this event is meant in reference to the listener (trained or untrained), or whether salience is a function of the written score. Furthermore, Harrison's concession that notated meter change does not include the phenomenon of irregularly accented beat patterns occurring within a consistently notated meter is brushed off too quickly, especially given the fact that perceptual salience is the strongest argument in favor of notated meter change as a metric for analysis in the present study. Thus, while notated meter change is a concise operationalization of this stylistic feature, it leaves out a large body of perceptually relevant data.

\section{POSSIBLE AVENUES FOR FUTURE STUDY}

In addition to membership within the Apaches, Harrison looks at metric complexity in relation to several social factors, including compositional school and generational membership. The data showed that, compared to other members of their generation, the Apaches did not show significant differences in meter change rate within their compositions. It is possible, however, that generational membership is not the most wellcontrolled way of looking at how a composer's cultural and historical context might influence their aesthetic goals. While a composer's generational cohort would likely have at least some impact on their musical style, this seems like a far less influential social factor than other related metrics such as year of composition, teacher-student relationships, school of composition, or even artistic response to historically significant events. This, of course, is an empirical question, which Harrison does touch upon, showing there to be an effect of composition year in the Zero-Inflated Negative Binomial Model B [2] shown in Table 3. I would argue this to be a more musicologically relevant observation than generation membership, yet this comparison is largely left out of the discussion.

Harrison's overall conclusion is that the Apaches were slightly more extreme than their peers in an existing compositional trend towards greater metrical complexity in French music during the $19^{\text {th }}$ century. Figure 3 demonstrates this trend, highlighting that the Apaches began using more frequent meter changes slightly before their generational peers, and the control group of French composers selected later followed suit. As stated above, the composition year is related to the increased meter change rate. However, the composer's social group seems to be a co-variate in this relationship given the trends shown in Figure 3. Harrison mentions conducting a network analysis of this corpus in the future, based on Rogers' theories on the diffusion of innovations (2003). The co-variant effect of composer group and year of composition on meter change rate would be a useful point of entry for this analysis, allowing analytical connections to be drawn between composers' individual social relationships and broader trends in meter change rate during the stylistic period at hand.

\section{ACKNOWLEDGEMENTS}

This article was copyedited by Annaliese Micallef Grimaud and layout edited by Diana Kayser. 


\section{NOTES}

[1] Correspondence can be addressed to: Samantha Burgess, School of Music, Ohio State University, 1899 College Rd N, Columbus, OH 43210. Email: burgess.318@osu.edu.

[2] The Zero Inflated Negative Binomial model can be used to analyze data sets with a large number of meaningful zeros, sorting them into two conditional classes. Harrison uses this model to account for the cultural and stylistic likelihood of pieces with no examples of notated meter change.

\section{REFERENCES}

Huron, D. (2001). What is a musical feature? Forte's analysis of Brahms's Opus 51, No. 1, revisited. Music Theory Online, 7(4). Retrieved from https://mtosmt.org

Jacoby, N., \& McDermott, J. H. (2017). Integer Ratio Priors on Musical Rhythm Revealed Cross-culturally by Iterated Reproduction. Current Biology: CB, 27(3), 359-370. https://doi.org/10.1016/j.cub.2016.12.031

Janssen, B. (2018). Retained or Lost in Transmission: Analyzing and Predicting Stability in Dutch Folksongs. $\mathrm{PhD}$ thesis, University of Amsterdam, Netherlands. http://www.illc.uva.nl/cms/Research/Publications/

Dissertations/DS-2018-01.text.pdf

Labov, W. (1972). Sociolinguistic patterns. Philadelphia, PA: University of Pennsylvania Press.

Meyer, L. (1989). Style and music: history, theory, and ideology. Philadelphia, PA: University of Pennsylvania Press.

Rogers, E. (2003). Diffusion of innovations ( $5^{\text {th }}$ ed.). New York, NY: The Free Press.

Shanahan, D., \& Albrecht, J. (2019). Examining the Effect of Oral Transmission on Folksongs. Music Perception: An Interdisciplinary Journal, 36(3), 273-288. https://doi.org/10.1525/mp.2019.36.3.273 